\title{
SÍ NTESIS, COMPOSICIÓN Y MODIFICACIÓN DE LA GRASA DE LA LECHE BOVINA: Un nutriente valioso para la salud humana
}

\author{
SYNTHESI S, COMPOSI TI ON AND MODI FI CATI ON OF THE \\ BOVI NE MI LK FAT: A valuable nutrient for the human health
}

\author{
Joaquín Angulo $A^{1,2 *}$, M.Sc, Liliana Mahecha $L^{2}$, M.Sc, Martha Olivera $A^{1}$, \\ Dr.Sci.Agr. \\ ${ }^{1}$ Universidad de Antioquia, Facultad de Ciencias Agrarias. Grupo de investigación \\ Biogénesis. ${ }^{2}$ Grupo de Investigación en Ciencias Agrarias GRICA. AA 1226, Medellín, \\ Colombia.*Correspondencia: joaquinangulo@gmail.com
}

Recibido: Septiembre 10 de 2008; Aceptado: Agosto 10 de 2009

\section{RESUMEN}

Se presenta una revisión sobre la composición, estructura y mecanismo de síntesis de la grasa de la leche en la glándula mamaria bovina y del efecto de la suplementación con ácidos grasos insaturados (AGI) sobre la cantidad y calidad de la grasa. Se resalta la importancia de la suplementación con aceites vegetales más aceite de pescado; se sugiere no generalizar el efecto de AGI como negativo sobre la cantidad de grasa de la leche; se muestra la necesidad de relacionar diferentes AGI con la vía regulatoria SREBP y con diferentes enzimas lipogénicas; y se incentiva la investigación del efecto de AGI sobre la composición de ácidos grasos de la leche y su distribución posicional dentro de la estructura lipídica.

Palabras clave: Ácidos grasos, glándula mamaria, lípidos, vacas.

\section{ABSTRACT}

It presents a review about the composition, structure and mechanism of milk fat synthesis in the bovine mammary gland, and about the effect of unsaturated fatty acid (UFA) supplementation on the amount and quality of milk fat. It is enhanced the importance of the supplementation with vegetable plus fish oils; it is suggested that the effect of UFA should not be remarked as negative on the amount of milk fat; It is showed the necessity of relating different UFA with the SREBP's regulatory way, and with different lipid enzymes; and it is promoted research about the effect of UFA on the milk fatty acid composition and their positional distribution into the lipid structure.

Key words: Fatty acids, mammary gland, lipids, cows. 


\section{NTRODUCCIÓN}

La preferencia de los consumidores ha marcado el camino a seguir en la producción de alimentos de origen animal a través de los años. El interés por productos saludables se ha convertido en un aspecto prioritario para la competitividad de la ganadería en el mundo. Especial interés se ha puesto en la composición de la grasa de los rumiantes toda vez que algunos de sus componentes - la mejoría en la relación entre algunos de ellos han sido asociados con efectos positivos para la salud humana. El ácido ruménico ó ácido linoleico conjugado (CLA, C18:2, cis- 9 trans-11) y el ácido trans vaccénico (TVA, C18:1 trans-11) han sido reportados con efectos benéficos para el cáncer humano mientras que una apropiada relación de ácidos grasos (AG) n- $6 / n-3$ ha sido asociada con reducción en enfermedades cardiovasculares, con reducción de células cancerosas, y con disminución de la inflamación en pacientes con artritis (1-5).

Considerando el efecto benéfico que la composición de la grasa de la leche puede representar para la salud humana, la investigación sobre su manipulación a través de la dieta ha estado enfocada en los últimos años hacia el incremento en el contenido de CLA y TVA, así como a la búsqueda de una relación apropiada de $n-6 / n-3$ a través de la adición de ácidos grasos insaturados (AGI). Grandes avances se han encontrado hasta el momento. Sin embargo, la investigación continúa en la obtención de mejores valores así como de una mayor estabilidad en los resultados, razón por la cual se le ha dado un gran énfasis al entendimiento de los efectos de la suplementación con AGI sobre el mecanismo de síntesis de la grasa de la leche y su regulación. No obstante, a pesar de los resultados encontrados, la utilización de AGI a nivel de finca no ha tenido una respuesta proporcional, posiblemente por los efectos colaterales que reportan disminución de la grasa de la leche. Por lo tanto, para incrementar el uso de estos AG en la suplementación de rumiantes con miras al mejoramiento de la calidad de la grasa para la salud humana, es necesario entender mejor por qué baja la grasa de la leche y encontrar alternativas para mejorar la composición de la grasa de la leche sin detrimento en la cantidad de grasa producida. Diversos investigadores han trabajado y continuán trabajando en este tópico enfocados en la fisiología de síntesis de la grasa de la leche. Este documento presenta una revisión sobre la composición, estructura y mecanismo de síntesis de la grasa de la leche en la glándula mamaria bovina y sobre el efecto de la suplementación con AGI en la cantidad y calidad de la grasa.

\section{COMPOSI CIÓN LI PÍ DI CA DE LA LECHE BOVI NA Y ESTRUCTURA DEL GLÓBULO DE GRASA}

La leche bovina se encuentra conformada aproximadamente por $98 \%$ de triglicéridos, menos del $2 \%$ por lípidos polares (fosfoglicéridos, esfingolípidos y colesterol), y por pequeñas cantidades de ácidos grasos libres (AGL), mono, di y triglicéridos (6). Los triglicéridos están constituidos por una unidad de glicerol al que están esterificados tres AG en las posiciones sn-1, sn-2 y sn-3 mientras que los lípidos polares varían su estructura de acuerdo al grupo al que se refiera, pudiéndose encontrar al menos tres grupos en la grasa de la leche bovina.

El primer grupo son los fosfoglicéridos, entre los que se encuentran fosfoglicéridos y plasmalógenos. Los fosfoglicéridos son los más abundantes y conocidos, e incluyen en su estructura ácido fosfatídico. La diferencia principal entre plasmalógenos y fosfoglicéridos es que el $A G$ en el C-1 (sn-1) del glicerol contiene una especie alquil $\left(-\mathrm{O}-\mathrm{CH}_{2}-\right)$ o Oalquenil éter $(-\mathrm{O}-\mathrm{CH}=\mathrm{CH}-)$.

El segundo grupo son los esfingolípidos, que a su vez se dividen en fosfoesfingolípidos y glucolípidos. Los fosfoesfingolípidos incluyen en su estructura una ceramida, un grupo fosfato y un aminoalcohol; el más abundante esfingolípido es la esfingomielina. Los glucolípidos también poseen en su estructura una ceramida, pero no tienen fosfato ni alcohol; entre los principales glucolípidos se encuentran los cerebrósidos y gangliósidos.

El tercer grupo hace referencia al colesterol, un lípido esteroide formado por una molécula 
de ciclopentanoperhidrofenantreno constituida por cuatro carbociclos condensados, una cadena alifática y un grupo hidroxilo $(6,7)$.

La composición de AG varía entre los tipos de lípidos. Los AGI predominan en los fosfoglicéridos (70\% insaturados, 30\% saturados), mientras que los saturados predominan en los triglicéridos (30\% insaturados, $70 \%$ saturados), esfingolípidos (20\% insaturados, $80 \%$ saturados) y glucolípidos ( $20 \%$ insaturados, $80 \%$ saturados) (8). En términos generales podría decirse que la grasa de la leche bovina está compuesta por $70 \%$ AGS, $25 \%$ monoinsaturados y $5 \%$ poliinsaturados (PUFA). Sin embargo, esta composición puede ser mejorada, al disminuir la relación entre AGS y AGI a través de la dieta.

La distribución posicional de los AG también varía entre los tipos de lípidos y no es aleatoria. En los triglicéridos, Ios AG de cadena corta (AGCC) butírico $(4: 0)$ y caproico (6:0) son esterificados casi en su totalidad en la posición sn-3; los ácidos grasos de cadena media AGCM entre 8 y 14 carbonos así como el palmítico (C16:0) son preferencialmente esterificados en las posiciones sn-1 y sn-2; el ácido esteárico (C18:0) es selectivamente esterificado en la posición sn-1, mientras que el ácido oleico (C18:1) muestra preferencia por las posiciones sn-1 y sn-3 (9). La posición de los AG también muestra ciertas preferencias en los fosfoglicéridos. Es frecuente que el de posición sn-2 suela ser AGI, mientras que el que ocupa la posición sn-1 suele ser AGS (10).

Referente a la estructura, se conoce que los lípidos de la leche bovina se encuentran empaquetados dentro de glóbulos grasos, ver figura 1 . Su origen inicia con la síntesis de triglicéridos en el retículo endoplasmático liso seguida por su agregación en el retículo endoplasmático rugoso (RER), conformando lo que se conoce como núcleo del glóbulo de grasa (NGG) que se encuentran casi exclusivamente compuesto por triglicéridos (99.8\%) (11), con pequeñas cantidades de colesterol, vitaminas y otros componentes (Tabla 1) (6).
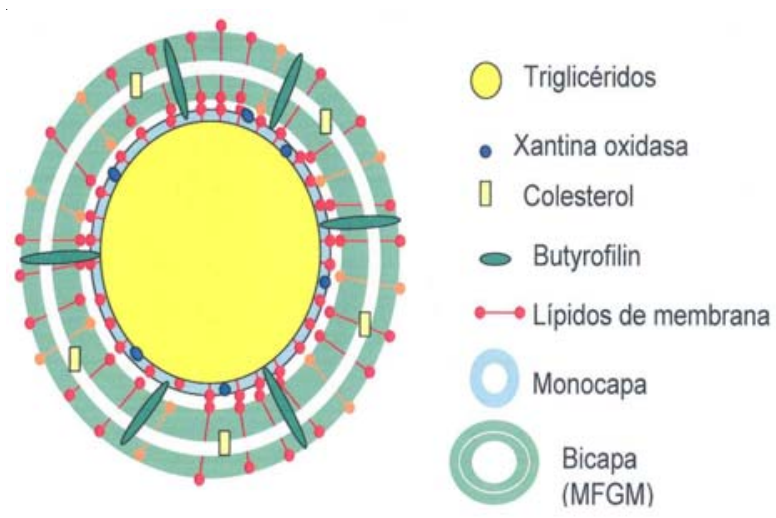

Figura 1. Estructura general del glóbulo de grasa de la leche bovina

El lugar exacto dentro del RER donde se lleva a cabo la conformación del NGG no es muy claro (12), pero se sabe que son liberados en el citosol de la célula epitelial mamaria (MEC, por su sigla en inglés) cuando tienen menos de $0.5 \mu \mathrm{m}$ de diámetro, de forma directa y no a través del aparato de golgi como sucede con la caseína ó las lipoproteínas en el hígado (13). Al salir al citosol, los NGG quedan revestidos con proteínas y lípidos de la membrana reticular, formando a su alrededor una monocapa en la que predominan fosfatidil y lisofosfatidil colina, y constituyendo lo que se conoce como microdroplet (Figura 2 \#1) (11). En el citosol, los microdroplets se unen entre sí y dan origen a macrodroplets ó droplets

Tabla 1. Composición del glóbulo de grasa de la leche bovina ( $\mathrm{mg} / \mathrm{kg}$ leche)

\begin{tabular}{lcc}
\hline \multirow{2}{*}{ Componentes } & \multicolumn{2}{c}{ Glóbulo de grasa de la leche } \\
\cline { 2 - 3 } & Núcleo & MFGM \\
\hline Proteínas & & 350 \\
\hline Glicéridos & & \\
\hline \multicolumn{1}{c}{ Triglicéridos } & 3800 & 670 \\
$\quad$ Diglicéridos & 100 & Trazas \\
$\quad$ Monoglicéridos & 10 & Trazas \\
\hline Fosfolípidos & Trazas & 210 \\
Esfingolípidos & Trazas & 80 \\
AG & 25 & Trazas \\
Esteroles & 100 & 15 \\
Vitaminas(A,D,E,K) & 2 & \\
Agua & 60 & 80 \\
Otros & 30 & \\
\hline
\end{tabular}


lipídicos citoplasmáticos (Figura 2 \# 2) que avanzan hacia la parte apical de la MEC por mecanismos que involucran elementos del citoesqueleto (11) y proteínas de la membrana del glóbulo de grasa de la leche (MFGM, por su sigla en inglés) (14).

Existen dos teorías sobre su mecanismo de secreción. La primera considera que los macrodroplets son secretados envolviendo parte de la membrana plasmática de la MEC, lo que pasa a conformar la MFGM, quedando finalmente constituido lo que se conoce como glóbulo graso de la leche (11) (Figura 2 \#3). La segunda teoría hace referencia a la secreción en vesículas (15). De acuerdo con la primera teoría, diversas proteínas de membrana, componentes tanto de la membrana plasmática apical de la MEC como de MFGM, ayudan a la secreción del glóbulo de grasa, entre las que se encuentran las mucinas MUC1 y MUC15, la enzima redox xantina oxidoreductasa, las proteínas integrales CD36 y butirofilin, y la proteína de unión a lípidos adipofilín (12).

Además de proteínas, también se ha encontrado que la MFGM está compuesta por triglicéridos, colesterol, fosfoglicéridos y esfingolípidos (Tabla 1) (incluyendo los dos últimos aproximadamente un $31.1 \%$ de fosfatidiletalonamina, $27.7 \%$ de esfingolípidos, $26.4 \%$ de fosfatidilcolina, $5.5 \%$ de fosfatidilserina, y $5.2 \%$ de fosfatidil inositol, $3 \%$ de plasmalógenos y $1.1 \%$ de gangliósidos) (6). Gracias a su composición, especialmente en lo referente a fosfoglicéridos y proteínas, la MFGM ha sido relacionada con propiedades anticolesterolémicas y anticancerígenas (5).

\section{MECANI SMO DE SÍ NTESI S DE LA GRASA DE LA LECHE.}

Síntesis de ácidos grasos. No todos los AG de la leche bovina se sintetizan en la glándula mamaria. En general, ellos provienen de tres fuentes: AG esterificados en los triglicéridos de las lipoproteínas que circulan en la sangre (procedentes de la dieta y el metabolismo ruminal) (Figura 2 \#4), AG no esterificados que circulan en la sangre provenientes de la movilización de reservas corporales (AG-
Albúmina) (Figura 2 \#5), y la síntesis de novo en la MEC (Figura 2 \#6) (16).

Los AGCC y el $50 \%$ de los AGCM saturados con un número par hasta de 16 Carbonos, son sintetizados de novo en el citoplasma de la MEC a partir del acetato y 3-hidroxi butirato que llegan en la sangre proveniente de la fermentación en el rumen, en reacciones catalizadas por las enzimas acetil CoA carboxilasa (ACC) y ácido graso sintetasa (FAS). El otro $50 \%$ de los AGCM saturados con un número par hasta de 16 Carbonos procede de lípidos circulantes en sangre que tienen su origen en la dieta, el rumen y la grasa movilizada de las reservas corporales $(17,18)$.

El origen del ruménico puede ser el rumen (7\%) o la síntesis de novo (93\%) en el retículo endoplasmático de la MEC, a partir del TVA que proviene del rumen. Este proceso es conocido como desaturación (Figura 2 \#7) y es llevado a cabo por medio del complejo enzimático $\Delta 9$ desaturasa conocido también como Stearoil CoA Desaturasa o SCD que lleva a cabo la formación de los ácidos miristoleico (C14:1), palmitoleico (C16:1), y oleico (C 18:1 cis9), utilizando como sustratos el ácido mirístico (C14:0), palmítico (C16:0), y esteárico (C18:0), respectivamente (17, 18). En la glándula mamaria bovina es posible la desaturación pero no la elongación de cadenas de más de 16 carbonos debido a que no existen las enzimas necesarias (19), por lo tanto, los AG de 18 ó más carbonos (excepto los que se originan como producto de la desaturación tales como el oleico y el ruménico), proceden de lípidos circulantes en sangre. Gran importancia se le ha concedido a la enzima lipoproteína lipasa (LPL) por ser la encargada de hacer el corte de los AG que vienen en la sangre y suministrarlos a la MEC para su utilización (Figura 2 \#8). A partir de estudios inmunohistoquímicos y bioquímicos, se ha encontrado que la LPL está localizada tanto en la superficie y dentro de la célula principal de los principales tejidos como en la superficie luminal de las células endoteliales vasculares. Sin embargo, aún no hay claridad del lugar exacto en la glándula mamaria. Algunos han encontrado que se origina en la MEC mientras que otros la han encontrado 


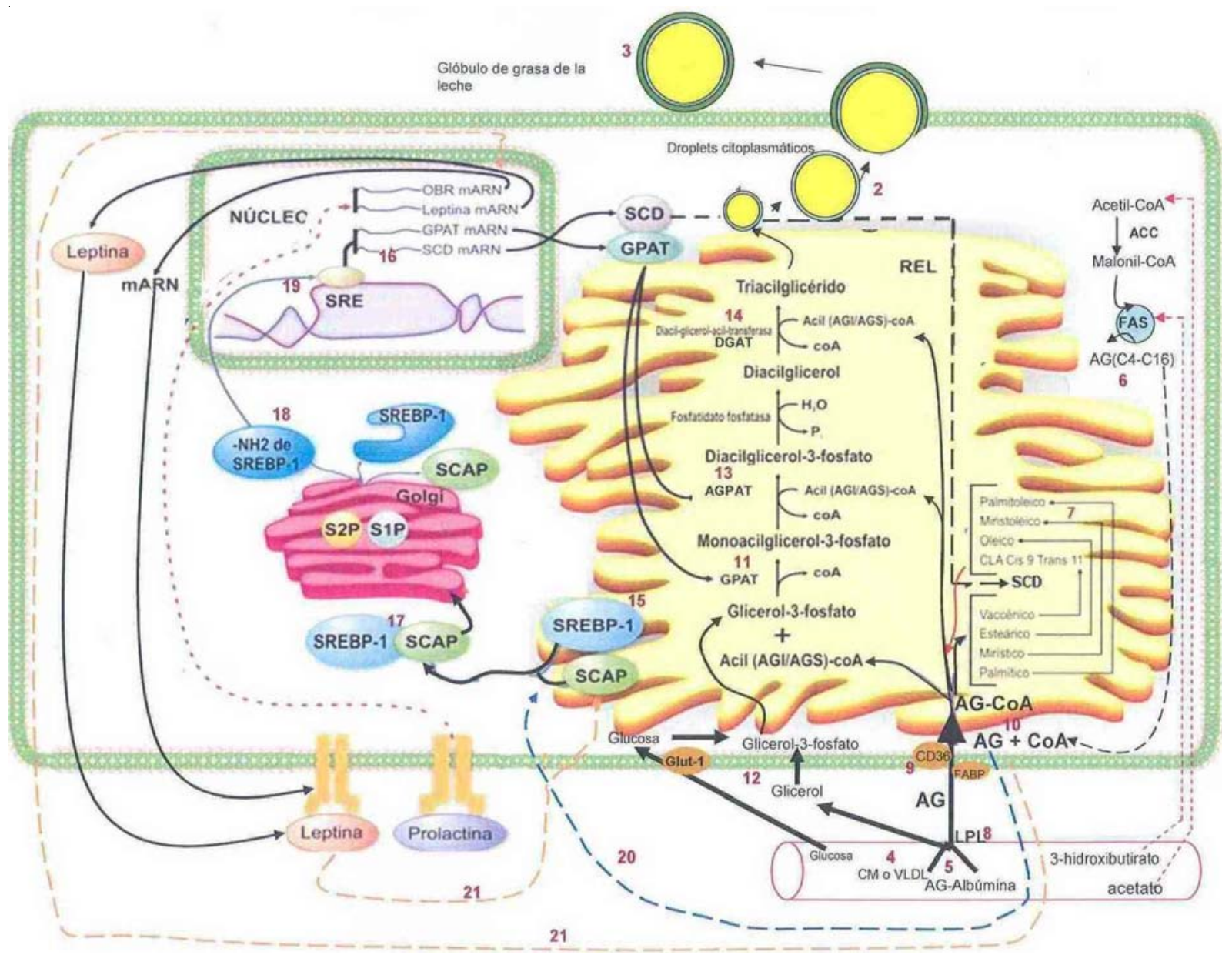

Figura 2. Mecanismo de síntesis y secreción de la grasa de la leche bovina

en los adipocitos mamarios localizados en las células intersticiales. Por lo tanto, se cree que posiblemente esta enzima es producida en los adipocitos, secretada y transportada a través de la MEC tanto hacia los capilares endoteliales como hacia el sitio de secreción de leche en la MEC (2). Una vez la LPL realiza el corte de AG en los capilares mamarios, estos deben atravesar lateralmente la bicapa lipídica de la membrana del capilar, luego cruzar células adyacentes que se encuentran entre el capilar y la MEC, para finalmente alcanzar la MEC, sin embargo, no existe claridad de cómo se logra este paso. Clegg et al (16) referencian la necesidad de un gradiente de concentración de AG, lo cual es posiblemente creado por traslocadores de AG o proteínas de enlace. Entre los más conocidos y estudiados hasta el momento se encuentran el FABP y la CD36 (Figura 2 \#9).
Síntesis de triglicéridos. Previo a la síntesis de triglicéridos, los AG son activados por la combinación con Coenzima A, formando los Acil- CoA (Figura 2 \#10). El primer paso en la biosíntesis de triglicéridos es la esterificación de un Acil-CoA con el glicerol 3 fosfato en la posición sn-1, en reacción catalizada por una glicerofosfatoaciltransferasa (GPAT) localizada en el retículo endoplasmático, dando como resultado un monoacilgricerol 3 fosfato (Figura 2 \#11) (2). El glicerol utilizado para la formación del glicerol 3-fosfato procede de la transformación de la glucosa que viene en la sangre ó del fraccionamiento de los triglicéridos incluidos en las lipoproteínas transportadas en la sangre (Figura 2 \#12). El segundo paso es la esterificación de otro Acil-CoA con el monoacilglicerol 3 fosfato en la posición sn-2, en reacción catalizada por la enzima Acilglicerolfosfato 
aciltranferasa ó Lisofosfatidil aciltransferasa (AGPAT ó LPAAT) (2) (Figura 2 \#13), la cual tiene una mayor afinidad por los AGS en el orden $\mathrm{C} 16>\mathrm{C} 14>\mathrm{C} 12>\mathrm{C} 10>\mathrm{C} 8$ (20); el producto final de esta reacción es el diacilglicerol-3-fosfato, Ilamado también ácido fosfatídico. El tercer paso es la eliminación hidrolítica del fosfato en la posición sn-3 del diacilglicerol 3 fosfato, seguida de una transferencia de otro grupo acilo procedente de un acil CoA, en reacción catalizada por la enzima diacilglicerol aciltranferasa (DGAT) (Figura 2 \#14) (2).

Síntesis de fosfoglicéridos. La mayor parte de los lípidos polares que se encuentran en la leche bovina, provienen de la membrana plasmática apical de la MEC y de la membrana reticular. En forma general, se conoce que los fosfoglicéridos, principales constituyentes en número de los lípidos de membrana presentes en la leche bovina, se sintetizan en la bícapa citosólica de la membrana del RE permitiendo que las cadenas de AG hidrofóbicas permanezcan clavadas en la membrana mientras se une a enzimas que catalizan sus reacciones con precursores del citosol. Para mantener estable la membrana, alguno de estos nuevos lípidos sintetizados son transferidos a la otra mitad de la bícapa (Lumen); esta transferencia ocurre gracias a una proteína de membrana llamada FLIPASA, resultando en un crecimiento de ambas mitades de la bícapa. En el proceso de síntesis, dos AG son unidos a la coenzima A, luego los acylcoA son unidos al glicerol 3 fosfato, produciendo ácido fosfatídico, el cual es simultáneamente insertado en la membrana. Posteriormente una fosfatasa convierte el ácido fosfatídico en diacilglicerol. Finalmente, diferentes grupos polares se unen al diacilglicerol dando lugar a la formación de fosfatidilcolina, fosfatidiletalonamina, ó fosfatidilserina. El fosfatidilinositol es formado a partir de ácido fosfatídico, y no a partir del diacilglicerol. (21).

\section{EFECTO DE LOS ÁCIDOS GRASOS I NSATURADOS SOBRE LA CANTI DAD DE GRASA DE LA LECHE}

Existen dos enfoques del efecto de los AGI sobre la cantidad de grasa de la leche: uno general y otro diferencial. El enfoque general se basa en resultados obtenidos en hígado de humanos y ratas, en donde se encontró que los AGI y en especial los PUFA indujeron la expresión génica de enzimas responsables de la oxidación de AG y reprimieron enzimas relacionadas con la lipogénesis (22). El enfoque diferencial considera que en la glándula mamaria bovina no siempre los AGI causan reducción de la síntesis de la grasa de la leche. Las razones podrían ser resumidas en tres aspectos principales:

Primero, porque no todos los AGI que llegan directamente a la glándula mamaria, procedentes de la dieta, tienen el mismo efecto regulatorio sobre las enzimas lipogénicas mamarias y/o sobre la síntesis de la grasa de la leche. La adición de ácido ruménico en MEC bovinas, no afectó el metabolismo lipídico mientras que el trans10 cis-12 CLA disminuyó la síntesis de triglicéridos (23); la adición in vitro de TVA y de ruménico mejoró la actividad de la enzima SCD en MEC bovinas, mientras que el oleico y el linoleico la disminuyeron (24); asimismo, la adición in vitro de TVA y de esteárico no afectó la transcripción del gen promotor de la SCD en MEC bovinas mientras que el linoleico y el oleico la disminuyeron (25).

Segundo, porque existen otros aspectos en la glándula mamaria que afectan la regulación que puedan causar ciertos $A G$ que vienen directamente de la dieta, lo cual no ha sido clarificado hasta el momento, pero que podría en cierto modo estar asociado con las relaciones de disponibilidad de ciertos $A G$ en la glándula mamaria. Posiblemente, a esto se deba el que hayan resultados contrastantes sobre el efecto de algunos AGI cuando se han trabajado in vitro directamente sobre la MEC bovina, en infusiones abomasales o intestinales, ó a través de lípidos protegidos. Se ha encontrado que la adición de ácido oleico ó linoleico en MEC bovinas disminuye la actividad de las enzimas lipogénicas ACC y FAS $(24,26)$. Sin embargo, Yonezawa et al (27) y Enjalbert et al (28) encontraron que la grasa de la leche aumentaba ó no había diferencia. Así mismo, Mahecha et al (1) no encontraron efecto sobre la grasa de la leche al suplementar con lípidos protegidos mientras que Ahnadi et al (29) encontraron reducción. 
Tercero, porque en los rumiantes el rumen impide que la mayor parte de AGI que se ingieren en la dieta, lleguen en forma intacta a la glándula mamaria, ya que son biohidrogenados parcial o totalmente por los microorganismos ruminales. Por lo tanto, en dietas en que los AGI no estén protegidos a la degradación ruminal, el efecto sobre la regulación de las enzimas lipogénicas depende no tanto del AG de la dieta sino de sus metabolitos ruminales, y estos metabolitos no siempre son los mismos ya que dependen de las interacciones generadas a nivel ruminal con otros nutrientes. Por ejemplo, se reporta que la suplementación de aceites vegetales en dietas bajas en fibra causan depresión de la grasa de la leche, mientras que con dietas altas en forraje no (3). Asimismo, se ha encontrado que la suplementación de aceite de pescado solo, causa depresión en la grasa de la leche (30), mientras que la combinación de aceite de pescado con aceite de girasol la incrementa (4). Algunos estudios en los que se ha obtenido incremento en trans-10 cis- 12 CLA; trans- 7 cis- 9 CLA, trans- 9 cis11 CLA, ó trans-10 18:1, se ha reportado disminución en la expresión de algunas enzimas lipogénicas y caida de la grasa de la leche $(31,32)$. Por el contrario, trabajos en los que no ha habido un cambio significativo en alguno de estos metabolitos, no se ha obtenido alteración en la grasa de la leche ó el cambio ha sido mínimo $(3,4,33)$. No obstante, aún falta por relacionar el efecto de una gran parte de metabolitos ruminales con diferentes enzimas que intervienen en la síntesis de la grasa de la leche. También es necesario profundizar en la vía de regulación de estos AG.

Hasta el momento, los pocos estudios realizados sobre regulación de AG en glándula mamaria bovina, han encontrado asociación entre la suplementación de algunos AGI y el cambio en la proteína de unión al elemento de respuesta a los esteroles (SREBP-1) (23, $25,31)$, razón por la cual se ha planteado como vía principal de regulación en la glándula mamaria bovina. SREBP-1 es una familia de proteínas sintetizadas como formas precursoras inactivas, las cuales se encuentran ancladas a la membrana del RE y a la membrana nuclear en una disposición de horquilla, como se observa en la figura 2 \#15. El gen de las enzimas lipogénicas que actúan en la glándula mamaria contiene un extremo SRE (Figura 2 \#16) al que se unen las SREBP. Ante la ausencia de un estímulo desencadenante, la SREBP se encuentra conformando un complejo con la proteína SCAP (SREBP cleavage activating protein; proteína activante del rompimiento de las SREBP) en el RE. Sin embargo, ante un estímulo desencadenante, la SCAP sufre un cambio conformacional y se desprende de su unión al RE, de forma que SCAP y SREBP migran al complejo de golgi (Figura 2 \#17) a través de vesículas (recubiertas de proteínas COP-II).

Estas vesículas también contienen una serina-proteasa inactiva de la familia subtilisina (Sitio-1 protease; SP1). En la membrana de golgi, la proteasa SP1 se activa y corta SREBP en el medio de su bucle hidrófilo lumenal. Tras este corte, SP2, una metaloproteasa transmembrana dependiente de zinc, que posiblemente reside en golgi de forma constitutiva, vuelve a cortar a SREBP en la región intramembrana del lado citoplasmático. Este proceso denominado "RIP" (regulated intermembrane proteolysis ó proteólisis de intermembrana regulada) libera la región aminoterminal (68 kDa) denominada forma madura ó activa (Figura 2 \#18), que contiene una señal de localización nuclear que interacciona directamente con el receptor citosólico llamado importina, permitiendo su transporte al núcleo. Una vez en el núcleo, SREBP puede unirse a las regiones SRE presentes en regiones promotoras de genes involucrados en la síntesis de lípidos y regular su expresión (Figura 2 \#19). (2,34).

Aunque se conoce que esta es la principal vía de regulación de enzimas lipogénicas por algunos AGI que han sido estudiados, aún no se conoce con claridad si los AGI que ingresan en la MEC desencadenan directamente la vía de la SREBP (Figura 2 \# 20) o si lo hacen de forma indirecta a través del estímulo de hormonas como la leptina y la prolactina (Figura 2 \#21) o ambos. Estudios realizados por Feuermann et al (35) y Yonezawa et al (27), han encontrado asociación entre la adición in vitro de AGI, 
el cambio en la expresión de mRNA de prolactina y leptina, y la síntesis de triglicéridos. Sin embargo, estos estudios no evaluaron la vía por la cual los AG actuaron para que la leptina ó ellos directamente, incidieran en la síntesis lipídica, tampoco se evaluó el efecto sobre la composición de los triglicéridos.

\section{EFECTO DE LA SUPLEMENTACIÓN CON ÁCI DOS GRASOS I NSATURADOS SOBRE LA CALI DAD DE LA GRASA DE LA LECHE}

Este efecto puede ser valorado de acuerdo al cambio en la composición de AG y de acuerdo al cambio en la estructura del triglicérido.

Aunque el incremento en AGI y reducción en AGS ha sido reportado benéfico para la disminución del riesgo a enfermedades cardiovasculares (36), y la disminución de la relación $n-6 / n-3$ ha sido asociada con reducción de problemas inflamatorios (1-5), el aumento de los ácidos ruménico y TVA en la grasa de la leche bovina han captado la mayor atención en la investigación. Diversos estudios han demostrado que la suplementación con aceites vegetales, aceite de pescado ó algas, ricos en AGI, tiene efectos positivos sobre el ácido ruménico y TVA, sobresaliendo los aceites de girasol y linaza por los niveles alcanzados $(3,4,12)$. Sin embargo, considerando que estos aceites pueden influenciar negativamente la cantidad de grasa de la leche, los estudios se han reorientado a la búsqueda de alternativas que puedan mejorar los niveles de ruménico y TVA sin perjudicar los niveles de grasa de la leche.

Hasta el momento se ha encontrado que la combinación de aceites vegetales con aceite de pescado puede tener el efecto buscado. No obstante, los resultados siguen siendo contrastantes. La inclusión de diferentes niveles de aceite de girasol y pescado en la dieta bovina ha resultado en mayor concentración de ruménico y TVA en la grasa de la leche sin alteración de la cantidad de grasa cuando se utilizaron niveles de $3 \%$ de aceite de girasol y $0.5 \%$ de aceite de pescado (3). Similares resultados fueron encontrados en niveles de TVA y ruménico, pero controversialmente, la proporción de grasa de la leche incrementó linealmente a medida que incrementó el aceite de pescado (4). Más investigación es necesaria a nivel del metabolismo de síntesis de la grasa de la leche en la glándula mamaria y de su relación con los metabolitos ruminales, así como de los niveles a utilizar en la combinación de estos aceites en la suplementación.

En contraste a los cambios en la composición de AG de la leche, la influencia de la suplementación sobre la estructura del triglicérido no ha sido muy evaluada. Estudios reportados por Valenzuela et al (37), en el humano, indican que los AG de cadena larga se absorben mejor en la posición sn-2, excepto el ruménico que se encuentra principalmente en posición sn-1 y sn-3 del triglicérido de la leche bovina y ha mostrado una mejor absorción y oxidación en ratas cuando está presente en estas posiciones que en sn- 2 (38). Por lo tanto, sería preferible que la posición sn-2 de los triglicéridos de la leche esté ocupada por AGI (excepto en el caso del ruménico). No obstante, los AGS son los que predominan en esta posición (39) y han sido asociados con problemas cardiovasculares (36). Así, cuando se suplementan bovinos con AGI con el objetivo de incrementar sus niveles en la leche y disminuir el de saturados, es también importante considerar la modificación que se ocasione en la posición de los AG. Algunos trabajos indican que es posible modificar la distribución estequiométrica de los $A G$ en la grasa de la leche bovina $(20,40)$.

\section{CONSI DERACI ONES FI NALES}

Día a día la investigación encuentra nuevos componentes tanto del núcleo como de la membrana del glóbulo de grasa de la leche bovina, relacionados con la salud humana. Por lo tanto, el potencial benéfico de la grasa de la leche continúa siendo atractivo para su exploración.

La suplementación con AGI provenientes de la mezcla de aceites vegetales y de pescado o algas) se considera una buena alternativa para el mejoramiento de la calidad de la grasa. No obstante, se necesita más investigación para evitar efectos negativos sobre la cantidad de la grasa. 
No se debe generalizar el efecto de los AGI como negativo sobre la SREBP1, sobre la actividad de las enzimas lipogénicas, ni sobre la producción de grasa de la leche. Se podría hipotetizar que existe un efecto individual. Algunos isómeros del CLA así como algunos isómeros trans $\mathrm{C} 18: 1$, se han encontrado como inhibidores de enzimas relacionadas con la síntesis de novo y por lo tanto con la depresión de la grasa de la leche mientras que el ácido vaccénico se vislumbra como posible activador de la SREBP1 y de algunas enzimas lipogénicas o por lo menos con un efecto neutro sobre algunas de ellas. El efecto de los demás insaturados no es claro y posiblemente se vea alterado por la relación en la disponibilidad entre algunos de ellos.
En un futuro cercano, la investigación deberá enfocarse no solo al efecto de la suplementación sobre la composición de AG de la leche sino también sobre su distribución posicional dentro de la estructura lipídica.

\section{Agradecimientos}

Los autores agradecen a Colciencias, a la Universidad de Antioquia, al Instituto para la Investigación en Animales Domésticos (FBN) (Alemania), y al Instituto Nacional de la Investigación Agronómica (INRA) (Francia), la financiación del proyecto de investigación No. 111545221319, que dio origen a este artículo de revisión.

\section{REFERENCIAS}

1. Mahecha L, Angulo J, Salazar B, Cerón M, Gallo J, Molina $\mathrm{CH}$ et al. Supplementation with bypass fat in silvopastoral systems diminishes the ratio of milk saturated/unsaturated fatty acids. Trop Anim Health Prod 2008; 40:209-216.

2. Bernard L, Leroux C, Chilliard Y. Expression and Nutritional Regulation of Lipogenic Genes in the Ruminant Lactating Mammary Gland. Adv Exp Med Biol 2008; 606:67-108.

3. Cruz-Hernandez C, Kramer JKG, + Kennelly JJ, Glimm DR, Sorensen BM, Okine EK et al. Evaluating the Conjugated Linoleic Acid and trans 18:1 Isomers in Milk Fat of Dairy Cows Fed Increasing Amounts of Sunflower Oil and a Constant Level of Fish Oil. J Dairy Sci 2007; 90:3786-3801.

4. Palmquist DL, Griinari JM. Milk fatty acid composition in response to reciprocal combinations of sunflower and fish oils in the diet. Anim Feed Sci Technol 2006; 131:358-369.

5. Spitsberg VL. Bovine milk fat globule membrane as a potential nutraceutical. J Dairy Sci 2005; 88:2289-2294.
6. Jensen RG, Ferris AM, Lammi-Keefe CJ. Symposium: Milk fat composition, function and potential for change. The composition of milk fat. J Dairy Sci 1991; 74:3228.

7. Fahy E, Subramaniam S, Brown HA, Glass CK, Merrill AH Jr, Murphy RC et al. A comprehensive classification system for lipids. J Lipid Res 2005; 46(5):83961.

8. Smith LM, Lowry RR. Fatty Acid Composition of the Phospholipids and Other Lipids in Milk. J Dairy Sci 1962; 45:581-588.

9. Månsson HL. Fatty acids in bovine milk fat. J Food Nutr Res 2008; 52. DOI: 10.3402/fnr.v52i0.1821.

10. Hawke J C. The distribution of fatty acids between the $a^{\prime}$-and $b$ - positions of the glycerophospholipids of buttermilk. J Lipid Research 1963; 4(3):255-259.

11. Heid HW, Keenan TW. Intracellular origin and secretion of milk fat globules. Eur J Cell Biol 2005; 84(2-3):245-58. 
12. Bauman DE, Perfield JW, Harvatine KJ, Baumgard LH. Regulation of Fat Synthesis by Conjugated Linoleic Acid: Lactation and the Ruminant model. J Nutr 2008; 138(2):403-409.

13. Stein O, Stein Y. Lipid synthesis, intracellular transport, and secretion II. Electron Microscopic Radioautographic Study of the Mouse Lactating Mammary Gland. J Cell Biol 1967; 34:251-263.

14. Reinhardt TA, Lippolis JD. Bovine milk fat globule membrane proteome. J Dairy Res 2006; 73(4):406-416.

15. Wooding FBP. The mechanism of secretion of the milk fat globule. J Cell Sci $1971 ; 9: 805-821$.

16. Clegg RA, Barber MC, Pooley L, Ernens I, Larondelleb Y, Traversa MT. Milk fat synthesis and secretion: molecular and cellular aspects. Livest Prod Sci 2001; 70:3-14.

17. Angulo J, Mahecha L, Giraldo CA, Olivera M. Prostaglandinas y grasa de la leche. Síntesis a partir de ácidos grasos poliinsaturados, en bovinos. En: Bioquímica, nutrición y alimentación de la vaca. Medellín-Colombia: Editorial Biogénesis; 2005.

18. Angulo J, Olivera M. Fisiología de la producción láctea en bovinos: Involución de la glándula mamaria, láctogenesis, galactopoyesis y eyección de la leche. En: Buenas Prácticas de producción de leche: contexto socioeconómico, morfofisiológico, sanitario y normativo. MedellínColombia: Editorial Biogénesis; 2008.

19. Chilliard $Y$, Ferlay A, Mansbridge RM, Doreau M. Ruminant milk fat plasticity: nutritional control of saturated, polyunsaturated, trans and conjugated fatty acids. Ann Zoot 2000; 49:181-205.

20. DePeters EJ, German JB, Taylor SJ, Essex ST, Perez-Monti H. Fatty Acid and Triglyceride Composition of Milk Fat from Lactating Holstein Cows in Response to
Supplemental Canola Oil. J Dairy Sci 2001; 84:929-936.

21. Cooper G.M. The Cell: A Molecular Approach 2d ed. Amer. Soc. Microbiol., Washington: and Sinauer Assoc., Sunderland, MA. Cap III: Cell Structure and function; 2000.

22. Moon YS, Latasa MJ, Griffin MJ, Sul HS. Suppression of fatty acid synthase promoter by polyunsaturated fatty acids. J Lipid Res 2002; 43(5):691-8.

23. Peterson D, Matitashvilli E, Bauman $D$. The inhibitory effect of trans- 10 cis12 CLA on lipid synthesis in bovine mammary epithelial cells involves reduced proteolytic activation of the transcription factor SREBP-1. J nutr 2004; 134 (10):2523-2527.

24. Jayan G, and Herbein J. "Healthier" dairy fat using trans-vaccenic acid. Nutr Food Sci 30 (6):304-309, 2000.

25. Keating A, Kennelly J, Zhao F. Characterization and regulation of the bovine stearoyl-CoA desaturase gene promoter. Biochem Biophys Res Commun 2006; 344:233-240.

26. Hansen HO, Knudsen J. Effect of exogenous long-chain fatty acids on lipid biosynthesis in dispersed ruminant mammary gland epithelial cells: Esterification of long-chain exogenous fatty acids. J Dairy Sci 1987; 70: 13441349.

27. Yonezawa T, Yonekura S, Kobayashi Y, Hagino A, Katoh A, Obara Y. Effects of Long-Chain Fatty Acids on Cytosolic Triacylglycerol Accumulation and Lipid Droplet Formation in Primary Cultured Bovine Mammary Epithelial Cells. J Dairy Sci 2004; 87:2527-2534.

28. Enjalbert F, Nicot MC, Bayourthe C, Moncoulon R. Odenal Infusions of Palmitic, Stearic or Oleic Acids Differently Affect Mammary Gland Metabolism of Fatty Acids in Lactating Dairy Cows. J Nutr 1998; 128(9):1525-32. 
29. Ahnadi CE, Beswick N, Delbecchi L, Kennelly JJ, Lacasse P. Addition of fish oil to diets for dairy cows. II. Effects on milk fat and gene expression of mammary lipogenic enzymes. J Dairy Res 2002; 69(4):521-31.

30. Rego OA, Rosaa HJD, Portugalb $P$, Cordeiroa R, Borbaa AES, Vouzelaa CM et al. Influence of dietary fish oil on conjugated linoleic acid, omega-3 and other fatty acids in milk fat from grazing dairy cows Livest Prod Sci 2005; 95:2733.

31. Harvatine $K$, Bauman DE. SREBP1 and Thyroid Hormone Responsive Spot 14 (S14) Are Involved in the Regulation of Bovine Mammary Lipid Synthesis during Diet-Induced Milk Fat Depression and Treatment with CLA. J Nutr 2006; 136:2468-2474.

32. Perfield JW, Lock AL, Griinari JM, Saebø A, Delmonte P, Dwyer DA et al. trans9, cis-11 conjugated linoleic acid reduces milk fat synthesis in lactating dairy cows. J Dairy Sci 2007; 90(5):2211-8.

33. Murrieta CM, Hess BW, Scholljegerdes EJ, Engle TE, Hossner KL, Moss GE et al. Evaluation of milk somatic cells as a source of mRNA for study of lipogenesis in the mammary gland of lactating beef cows supplemented with dietary highlinoleate safflower seeds. J Anim Sci 2006; 84:2399-2405.

34. Vernia S. Estudio del factor de transcripción SREBP1 en estados de resistencia a insulina. [Tesis Doctoral]. Valencia: Departamento de Bioquímica y Biología Molecular. Consejo Superior de Investigaciones Científicas Instituto de Biomedicina de Valencia. Universidad de Valencia; 2007.
35. Feuermann Y, Mabjeesh SJ, NivSpector L, Levin D, Shamay A. Prolactin affects leptin action in the bovine mammary gland via the mammary fat pad. J Endocrinol 2006; 191(2):407-13.

36. Castro-Bolaños M, Herrera-Ramírez C, Lutz-Cruz G. Composición, caracterización y potencial aterogénico de aceites, grasas y otros derivados producidos o comercializados en Costa Rica. Acta Med Costarric 2005; 47(1).

37. Valenzuela A, Sanhueza J, Nieto S. El uso de lípidos estructurados en la nutrición: una tecnología que abre nuevas perspectivas en el desarrollo de productos innovadores. Rev chil nutr 2002; 29(2):106-115.

38. Chardigny JM, Masson E, Sergiel JP, Darbois M, Loreau O, Noël JP et al. The position of rumenic acid on triacylglycerols alters its bioavailability in rats. J Nutr 2003; 133(12):4212-4.

39. Karupaiah T, Sundram K. Effects of stereospecific positioning of fatty acids in triacylglycerol structures in native and randomized fats: a review of their nutritional implications. Nutr Metab 2007; 4:16:1-17.

40. Christie WW, Clapperton JL. Structures of the triglycerides of cows' milk, fortified milks (including infant formulae), and human milk. Int J Dairy Tech 1982; 35:22-24. 